AperTO - Archivio Istituzionale Open Access dell'Università di Torino

\title{
Lipid oxidation products in the pathogenesis of inflammation-related gut diseases
}

\section{This is a pre print version of the following article:}

Original Citation:

\section{Availability:}

This version is available http://hdl.handle.net/2318/1643893

since 2019-05-11T14:57:13Z

Published version:

DOI:10.2174/0929867324666170619104105

Terms of use:

Open Access

Anyone can freely access the full text of works made available as "Open Access". Works made available under a Creative Commons license can be used according to the terms and conditions of said license. Use of all other works requires consent of the right holder (author or publisher) if not exempted from copyright protection by the applicable law. 


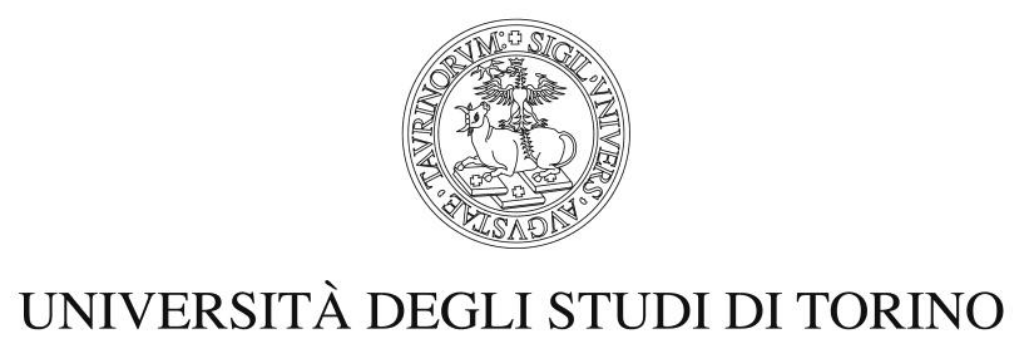

This is the author's final version of the contribution published as:

Sottero, Barbara; Rossin, Daniela; Poli, Giuseppe; Biasi, Fiorella. Lipid

oxidation products in the pathogenesis of inflammation-related gut diseases.

CURRENT MEDICINAL CHEMISTRY. 25 (11):1311 - 1326; 2018

DOI: $10.2174 / 0929867324666170619104105$

The publisher's version is available at:

https://benthamscience.com/journals/current-medicinal-chemistry/volume/25/issue/11/

When citing, please refer to the published version.

Link to this full text:

http://hdl.handle.net/2318/1643893 
Lipid oxidation products in the pathogenesis of inflammation-related gut diseases

\section{Barbara Sottero, Daniela Rossin, Giuseppe Poli, Fiorella Biasi}

Department of Clinical and Biological Sciences, University of Turin at San Luigi Gonzaga Hospital, Orbassano (Turin), Italy.

\section{Corresponding author:}

Fiorella Biasi

Department of Clinical and Biological Sciences, University of Turin at San Luigi Gonzaga Hospital, 10043 Orbassano (Turin), Italy

Phone number: 00390116705420; Fax number: 00390116705424

E-mail: fiorella.biasi@unito.it

Running title: lipid oxidation and intestinal inflammation

Total number of words: 10267 including references and Figure legends 


\begin{abstract}
A defective mucosal barrier function is the principal cause of the uncontrolled onset and progression of a number of human inflammatory gut diseases, most of which are characterized by chronic intermittent immune and inflammatory responses leading to structural intestinal damage, which can represent a potential risk for colorectal cancer development.
\end{abstract}

During the active disease phase the production of pro-inflammatory cytokines and chemokines, and the induction of oxidative reactions by activated leukocytes and epithelial cells represent the main event in intestinal inflammation.

Oxidative stress plays a key role in the development of intestinal damage. Indeed reactive oxygen species and their oxidized by-products regulate redox-sensitive signaling pathways and transcription factors, which sustain inflammation within the intestinal layer.

Polyunsaturated fatty acids and cholesterol are the principal targets of oxidative modifications. These lipids, which are cell membrane constituents or are present in food, readily undergo non-enzymatic oxidation to form chemically-reactive species that can induce a wide range of biological effects including inflammation, programmed cell death, and proliferation.

In this review we summarize the current knowledge on the role of lipid oxidation products in regulating redox pathways involved in the pathogenesis of inflammation-related gut diseases. In particular, lipid peroxidation end products such as isoprostanes and aldehydes, and cholesterol oxidation-derived oxysterols are taken into consideration.

We also discuss the hypothesis that controlling oxidative damage and consequently tissue local over-production of lipid oxidation products by using specific antioxidant and anti-inflammatory molecules in the diet may have clinical and therapeutic benefits.

Key words: gut; intestinal bowel disease; acrolein, isoprostanes, 4-hydroxynonenal, malondialdehyde, oxysterols, polyphenols 
Graphical abstract. Oxidative stress-derived lipid oxidation products, LPOs and COPs, are involved in the induction and maintenance of an inflammatory microenvironment leading to intestinal damage.

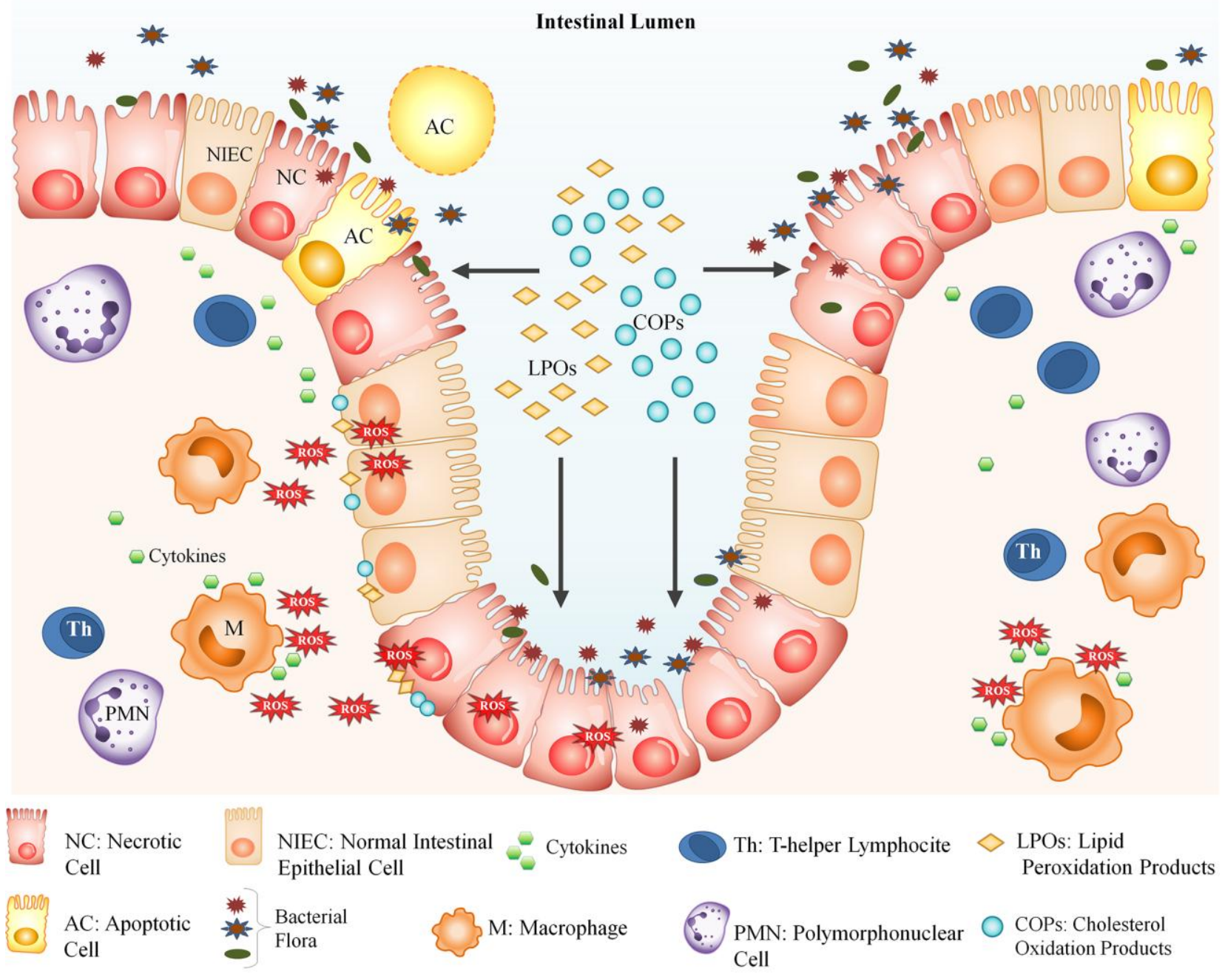




\section{Introduction}

Gut mucosa is constantly exposed to environmental and dietary antigens. It plays a primary role in the absorption of nutrients and in protecting the host against lumen pathogens and xenobiotics, for which a precise balance between proand anti-inflammatory processes controlled by the immune system is necessary. Inflammation is the locally- occurring physiological defense reaction in response to infections and tissue injury; it seeks to restore homeostasis by killing pathogens and activating tissue repair processes. The process is usually self-limiting due to the involvement of feedback mechanisms.

A defective mucosal barrier function is the principal cause of the uncontrolled onset of inflammation involved in the pathogenesis of a number of intestinal diseases, including irritable bowel syndrome (IBS) [1], inflammatory bowel disease (IBD) [2], and pauchitis [3]. IBD, comprising Crohn's disease (CD) and ulcerative colitis (UC), are the bestknown intestinal diseases; they are characterized by chronic intermittent immune and inflammatory responses that induce alternating active and remission periods of the disease.

Massive gut infiltration by activated leukocytes followed by the production of a wide spectrum of oxidants, cytokines, chemokines, and eicosanoids is the main feature of these intestinal diseases. Notably, during inflammation a condition of oxidative stress is established, due to the excess of reactive oxygen species (ROS), such as $\mathrm{O}_{2}{ }^{-{ }^{-}}, \mathrm{H}_{2} \mathrm{O}_{2}, \mathrm{NO}$ and $\mathrm{HOCl}$. These are generated in IBD by recruited inflammatory cells and mucosa-resident cells as an abnormal antimicrobial response. Conversely, ROS and their oxidized by-products regulate redox-sensitive signaling pathways and transcription factors, which maintain active inflammation within the intestinal layer, thus damaging gut barrier integrity.

Notably, structural and functional defects of the intestinal barrier, and the establishment of an inflammatory response, comprise a precancerous condition from which colorectal cancer (CRC) can develop [4]: many cases of CRC show marked activation of the redox-sensitive transcription factor Nuclear Factor $\kappa \mathrm{B}(\mathrm{NF}-\kappa \mathrm{B})$. Activation of NF- $\kappa \mathrm{B}$ via ROS generation during inflammation strongly supports carcinogenesis [5].

Furthermore, gut contact with microbiota can result in redox signaling, which involves $\mathrm{O}_{2}{ }^{--}$generation through catalytic activities of enterocytic NADPH oxidase 1 (NOX1) and phagocytic NADPH oxidase 2 (NOX2) enzymes [6]. This mechanism might be sufficient to aggravate intestinal inflammation in IBD, in which the NF- $\kappa \mathrm{B}$ signaling pathway is persistently activated by pathogen recognition receptors, namely Toll-like receptors (TLRs) and nucleotide-binding oligomerization domain (NOD)-like receptors (NLRs) [2]. In particular, NLRs are actively involved in the response against intestinal antigens: they can activate mitogen-activated protein kinases (MAPKs) and NF- $\mathrm{B}$ via formation of the NOD signalosome platform, or can form pro-caspase-1 inflammasome protein complexes, such as the nucleotidebinding oligomerization domain, leucine rich repeat, and pyrin domain containing 1 and 3 (NLRP1 and NLRP3). 
NLRP3 activity is up-regulated by high concentrations of ROS, produced both through NOX hyper-activation and through mitochondria malfunctioning; it is probable that this helps to exaggerate the inflammatory response in the intestine $[7,8]$.

The principal targets of ROS action are lipids, in particular polyunsaturated fatty acids (PUFAs) and cholesterol, which are cell membrane constituents or are exogenously present in food. These lipids readily undergo non-enzymatic oxidation to form chemically-reactive carbonyl compounds and hydrocarbons; these induce a wide range of biological effects including sustained inflammation, programmed cell death, and proliferation. Further, the enzymatic oxidation of membrane PUFAs by cyclooxygenases (COXs) and lipoxygenases (LOXs) gives rise to the well-known inflammatory mediators known as eicosanoids [9].

It is fundamental to understand where and how lipid oxidation products act on the redox pathways involved in the pathogenesis of intestinal diseases characterized by chronic inflammation, in order to develop prognostic and riskassessment schemes, and to improve anti-inflammatory strategies. This review reports the most relevant findings concerning the influence of lipid oxidation products in modulating intestinal inflammation, and highlights the importance of diet in maintaining redox balance, which is an emerging field for gut disease research.

\section{PUFA-derived oxidation products and their prevalence in intestinal inflammation}

PUFAs are essential fatty acids obtained only from food. Of the unsaturated lipids, the w6-PUFAs arachidonic acid (AA) and linoleic acid (LA) are required in humans because they are constituents of phospholipid membranes, and play significant roles in cellular membrane fluidity and enzyme activities. The high concentration of PUFAs incorporated in phospholipid membranes makes them prime targets for reactions with oxidizing agents. They provide the main substrate for enzymatic and non-enzymatic oxidative reactions.

AA and LA become major targets of ROS attack which initiates lipid peroxidation as a mechanism of lipid chain cleavage. Of note, AA undergoes oxidation more readily than LA, because of the greater availability of bisallylic positions susceptible to ROS attack.

The lipid peroxidation chain reaction consists of three steps: initiation, propagation, and termination. In the first phase, oxidants, for example free radicals, attack lipid carbon-carbon double bond(s), abstracting hydrogen and inserting oxygen. During the propagation phase, the resulting peroxyl radical intermediates undergo further cyclization, oxido-reduction, and/or fragmentation, leading to the formation of more chemically stable end-products. Cyclization reactions of peroxyl radicals are responsible for the generation of different sets of isoprostanes (IsoPs). The most 
important biologically-significant IsoPs formed non-enzymatically are the F2-isoprostanes (F2-IsoPs), which derive from AA auto-oxidation [10].

Conversely, $\beta$-scission of lipid hydroperoxide $\mathrm{C}$ - $\mathrm{C}$ bonds yields a broad array of smaller fragments, three to nine carbons in length, mainly grouped as 2-alkenals, ketoaldehydes and 4-hydroxy-2-alkenals [11, 12]. Among aldehydes produced as end-products of lipid peroxidation, acrolein, malondialdehyde (MDA) and 4-hydroxynonenal (HNE) are the carbonyl compounds most widely studied, due to their strong activity towards cell macromolecules, which may result in redox imbalance and inflammation, impairing the mucosal barrier.

Figure 1 shows the chemical structures of the main PUFAs and of their non-enzymatically oxidized derivatives of biological significance in inflammatory intestinal diseases.

AA is the main substrate for COX activity; this gives rise to eicosanoids including prostaglandins (PGs) such as PGE2, which are involved in the inflammatory response, promoting chemotaxis and activity of phagocytes. Increased activity of the inducible COX-2 is considered to be a parameter of inflammation, both in colitis and in colitis-associated cancer [13]

\section{Ф-6-PUFA}
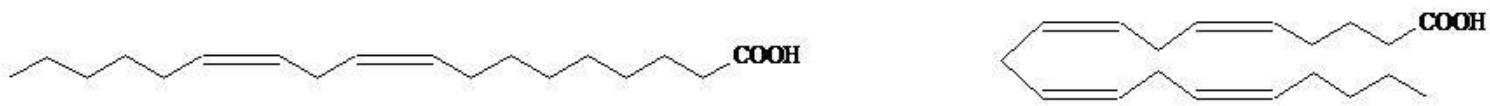

LAC18:2

AAC20:4

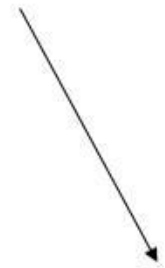

Free Radical Oxidation

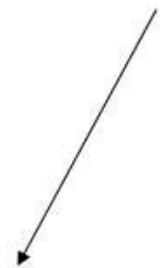<smiles>CCCCCC(O)/C=C/C(C)=O</smiles>

HNE<smiles>CCCCC/C=C/CC1C(O)CC(O)C1/C=C/C(O)CCCC(=O)O</smiles>

\section{Cyclization \\ Lipid
Hydroperoxides}

Fragmentation

F2-isoP<smiles>C=CC(C)=O</smiles>

Acrolein

Figure 1. Structures of the main oxysterols derived from cholesterol oxidation. 


\subsection{Isoprostanes}

$\mathrm{F}_{2}$-IsoPs have been extensively studied as markers of oxidative stress in human disease, as attested to by numerous papers, extensively reviewed by Milne and co-workers [10]. These compounds have been called prostaglandin-like, because they possess the characteristic F-ring of prostaglandins F2 $\alpha$. They are generated independently of the cyclooxygenase enzyme, and have been detected in tissues, blood, and urine. They have been shown to increase in plasma and urine samples in a number of cardiovascular, pulmonary and neurological diseases that are correlated to oxidative stress [14]. However, very few studies have evaluated F2-IsoPs production as a marker of intestinal inflammation in animal models [15-19]. F2-IsoPs, together with 11-dehydro-thromboxane B2, have been found elevated in the urine of patients with active IBD; the parameters decreased after anti-Tumor Necrosis Factor $\alpha$ (TNF $\alpha$ ) therapy with infliximab in responder IBD patients [20]. Conversely, a study in pediatric IBD patients showed inconsistent evidence of inflammation and low levels of F2-IsoPs in exhaled breath condensate samples [21].

\subsection{Acrolein}

Acrolein is the most reactive 2-alkenal commonly detected in pollution, burning of fat-containing foods, and smoking. It is thus mainly considered to be an environmental pollutant, exposure to which by inhalation induces severe irritating effects on mucous membranes, especially in the eyes and upper respiratory tract [22]. However, acrolein can also be produced endogenously by lipid peroxidation. Due to its strong electrophilic activity it has been considered genotoxic; it acts by inducing acrolein-deoxyguanosine (Acr-dG) DNA adducts, as well as protein adducts associated with carcinogenesis $[23,24]$.

Acrolein has been shown to be differentially distributed in colon adenomas and in CRC depending on tumor degree, and has been associated with transition from benign to malignant colon tumors [25]. A tenfold increase in Acr$\mathrm{dG}$ has been detected in CRC cells after silencing aldo-keto reductase 1B10, whose function is to protect cells from carbonyl damage by converting $\alpha, \beta$-unsaturated carbonyl compounds into less-toxic alcoholic forms [26].

Conversely, the formation of Acr-dG has been found to correlate with the number of double bonds in PUFAs: thus they are mainly produced from $\omega-3$ docosahexaenoic acid (DHA) and eicosapentaenoic acid, and to a lesser extent from AA and LA. HT-29 human colon cancer cells treated with acrolein showed increased Acr-dG levels and augmented apoptosis; in parallel, the same cells treated with DHA showed increased Acr-dG levels correlated with the induction of apoptosis. This evidence suggests that cell production of acrolein, with increased Acr-dG levels, is a possible mechanism whereby DHA might induce apoptosis, and consequently protect against colon tumorigenesis [27]. 
The bioactive derivative of acrolein, cinnamaldehyde, is indeed known for its antiproliferative and pro-apoptotic effects, and is now considered as having anticancer properties consisting in modulating cell signaling pathways: for instance, it inhibits survival PI3K/Akt signaling in a number of CRC cells [28] and activates cytoprotective antioxidant response in human epithelial colon cells by inducing Nuclear Factor-Erythroid 2-Related Factor 2 (NRF2) [29].

\subsection{MDA}

Malondialdehyde (MDA) is the most abundant small-chain ketoaldehyde produced by lipid peroxidation, and is among the most common parameters used to detect oxidative stress. It is typically quantified by a colorimetric assay based on the reaction between MDA and thiobarbituric acid to form thiobarbituric acid (TBA) reactive substances (TBARS) in human fluids. The assay is employed in a number of diseases characterized by inflammation, including intestinal diseases.

Increased MDA tissue levels have been detected in inflamed colonic tissues induced in rodents [30-33], by the administration of dextran sodium sulfate (DSS) in mice, or trinitrobenzene sulfonic acid (TNBS) in rats. These two chemicals are commonly employed in inducing experimental colitis [34, 35].

MDA is also routinely used in clinical studies as a lipid peroxidation marker; its level has been evaluated in colonic tissues and in plasma from IBD patients. Plasma MDA levels did not differ between IBD patients and normal subjects [36, 37]. Conversely, more recent studies have reported a positive correlation between MDA and disease severity, suggesting a role for oxidative stress in the development and worsening of inflammation in IBD. MDA has been shown to be elevated in $\mathrm{CD}$ patients, and to be the best $\mathrm{CD}$ predictor, alongside $\mathrm{C}$ reactive protein increase during inflammation [38]. Increased MDA levels, associated with acute inflammation, and a marked increase in NOX1 expression, were evidenced in fresh colon tissues of mice in which colitis had been induced by TNF $\alpha$ treatment [39].

In another study, both active and remission CD patients showed a significant increase in MDA plasma concentration compared to healthy subjects; MDA was significantly lower in inactive than that in active disease. In the same study, levels of 8-hydroxy-2'-deoxyguanosine (8-OHdG), which is considered a marker of DNA oxidative damage, were permanently elevated in both active and inactive CD patients, reinforcing the hypothesis of IBD as a precancerous disease [40]. The inhibition of mitochondrial potential that has been observed in active CD suggests that dysfunctional mitochondria may be a major site of the ROS overproduction associated with mucosal damage in IBD $[40,41]$. Contrasting results reporting levels of oxidative stress in terms of MDA production might be due to the different methods and instruments used: a variety of substances other than MDA are also reactive toward TBA, thus affecting method specificity. The sensitivity of the assay has increased in recent years thanks to combined use of more sophisticated new-generation instruments, such as HPLC or Gas Chromatography/Mass Spectrometry (GC/MS) [42]. 


\subsection{HNE}

Among 4-hydroxy-2-alkenals, 4-hydroxy-2-nonenal (HNE) has been recognized as an important lipid molecule of pathophysiological interest. The human plasma concentration of free F2-IsoP is of nanomolar order, while HNE ranges from nanomolar to micromolar levels [11]. In particular, the normal HNE concentration in human tissues and plasma has been estimated to be in the range $0.05-5 \mu \mathrm{M}$, while in oxidative-damage-related diseases its concentration can be as high as $100 \mu \mathrm{M}$ or above. This aldehyde can be measured by specific assays including HPLC and GC/MS or immuno-chemical analyses [43-45].

HNE levels in different organs, as well as those of other lipid oxidation products, may also be influenced by diet [46-48]. For instance, the digestive tract is frequently the first target of dietary compounds containing carbonyl compounds. In particular, Larsson and colleagues demonstrated that aldehyde levels are higher in the intestinal lumen than it was in meals containing cod liver oil, fish or fish oil, suggesting the gastrointestinal tract may be involved in promoting dietary lipid oxidation during digestion. Intestinal cells may thus for several hours be exposed to the action of elevated amounts of reactive aldehydes derived from food [49].

Because of its strong electrophilic character, HNE forms chemical adducts with DNA, proteins, and aminecontaining lipids; the most important chemical reactions are Michael additions and Schiff base formation. Its amphiphilic property and relatively long half-life makes it a candidate for the propagation of action distant from the production site, to other cells, where it tends to quickly react with macromolecules [43].

Proteins are quantitatively the most important group of biomolecules targeted by HNE; the resulting stable proteinadducts are readily detectable by using antibodies that specifically recognize the HNE-histidine epitope [44, 50, 51].

The wide range of effects produced by HNE depend on the concentration reached in cells or tissues. High HNE levels can exert deleterious events, including cytotoxicity, while at low concentrations HNE may be considered as a second messenger of free radical-mediated reactions that modulate important cell functions, such as enzyme activities, cell signal transduction, and gene expression [43, 52].

HNE's involvement in the pathogenesis of certain human diseases characterized by the marked activation of inflammatory processes has been established unequivocally $[43,52,53]$. Increased HNE levels have been found in the intestinal mucosa and in the plasma of CD patients [54].

The primary involvement of HNE in cytotoxicity is related to its metabolism, in particular its conjugation with glutathione catalyzed by glutathione-S-transferase, making the aldehyde less toxic/genotoxic. However, this process affects the antioxidant defenses: for instance, increased levels of HNE and MDA, together with a decrease in both reduced glutathione (GSH) content and SOD/CAT antioxidant enzymes, have been detected in inflamed mucosa from 
colitic mice, in which inflammation was experimentally induced by DSS or TNBS [55, 56]. CRC cells showing low levels of glutathione-S-transferase have been found to be more susceptible to HNE treatment in terms of increased DNA damage [57]. Notably, increased levels of HNE-modified DNA bases have been found in the inflamed colon mucosa of patients suffering from CD, UC, and chronic pancreatitis [58]. Increased formation of HNE-protein adducts has also been found to be inversely associated with antioxidant defenses in human colon cancer tissues [59].

Low HNE cell concentrations (1 to $10 \mu \mathrm{M}$ ) have been found to inhibit c-myc and p21 gene expression and telomerase activity in colon cancer cell lines [60, 61]. HNE-dependent induction of antioxidant adaptive response molecules, such as p382 and thioredoxin reductase 1, has been hypothesized as a mechanistic event that protects transformed cancer cells, defending them from further exposure to unfavorable oxidative stressors [62]. Further, HNE has been considered for a role in colon cancer aggressiveness, for its ability to interact with c-Jun N-terminal kinase (JNK) and Smads transducers, favoring the expansion of Transforming Growth Factor- $\beta 1$ resistant intestinal neoplastic cell clones $[63,64]$.

It is undoubted that HNE acts as a cell growth modulator; it is involved in cell proliferation, survival, apoptosis, and differentiation, especially by activating mitogen-activated protein kinases (mainly JNK), phosphoinositide-3-kinase, the catalytic alpha polypeptide (PIK3CA)-AKT pathways, and protein kinase C. However, it must be considered that the action of this aldehyde is very complex, depending on cell type and concentration [52]. As far as intestinal damage is concerned, HNE has been shown to affect intestinal barrier permeability, which is considered one of the main events occurring in both IBD and CRC development [65]. The high levels of HNE found in the intestinal mucosa in different experimental models of animal colitis have been associated with its ability to alter TLR-4/NF- $\mathrm{B}$ inflammatory pathway-dependent immune response $[55,66]$.

Although conclusive proof of the involvement of HNE in the pathogenesis of inflammatory intestinal diseases, and possibly also that of other aldehydes, including MDA and acrolein, has yet to be obtained, there is no doubt that HNE is a very likely candidate molecule for the role of triggering and sustaining a wide range of biochemical events underliying the development of these processes.

\section{Cholesterol-derived oxidation products and their prevalence in intestinal inflammation}

In a state of oxidative stress, cholesterol is another lipid compound susceptible to ROS attack. As a consequence of oxidative modifications, it gives rise to an extensive series of molecules, termed oxysterols, which are recognized to possess several effects of physiopathologic relevance.

\subsection{Oxysterols origin}


Autoxidation primarily occurs on the sterol nucleus at position 7, or at the 5,6 double bond, and generates, among

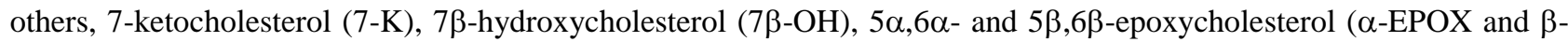
EPOX), and cholestan-3 $\beta, 5 \alpha, 6 \beta$-triol (TRIOL) (Figure 2) [67-69].

Other oxysterols also originate endogenously by the enzymatic action of specific cytochrome P450-dependent or independent hydroxylases, which yield the side-chain oxidized compounds 22-hydroxycholesterol (22-OH), 24hydroxycholesterol (24-OH) (also known as cerebrosterol), 25-hydroxycholesterol (25-OH) and 27-hydroxycholesterol (27-OH) [11], but also 7 $\alpha$-hydroxycholesterol (7 $\alpha-\mathrm{OH})$ [67-70] (Figure 2).

Cholesterol-rich food contains particularly high levels of oxysterols: these compounds originate in vivo in animals from both enzymatic and non-enzymatic reactions, and their content is further enhanced when food is exposed to heat, light, air and radiation during cooking, processing, and prolonged storage. The principal oxysterols detected in food are 7 $\alpha-\mathrm{OH}, 7 \beta-\mathrm{OH}, 7-\mathrm{K}, 5 \alpha, 6 \alpha-\mathrm{EPOX}, 5 \beta, 6 \beta-$ EPOX and TRIOL (Figure 2), commonly present as a mixture; together they account for $1-10 \%$ of the total cholesterol present in a meal, or even more [71]. Dietary oxysterols are absorbed completely in the bowel, cleared from the plasma lipoproteins, and taken up by different tissues and cells, where they are transformed through many cholesterol metabolic pathways. This wide variability in the metabolic fate of oxysterols makes it difficult to estimate their actual intake [70-72]. 


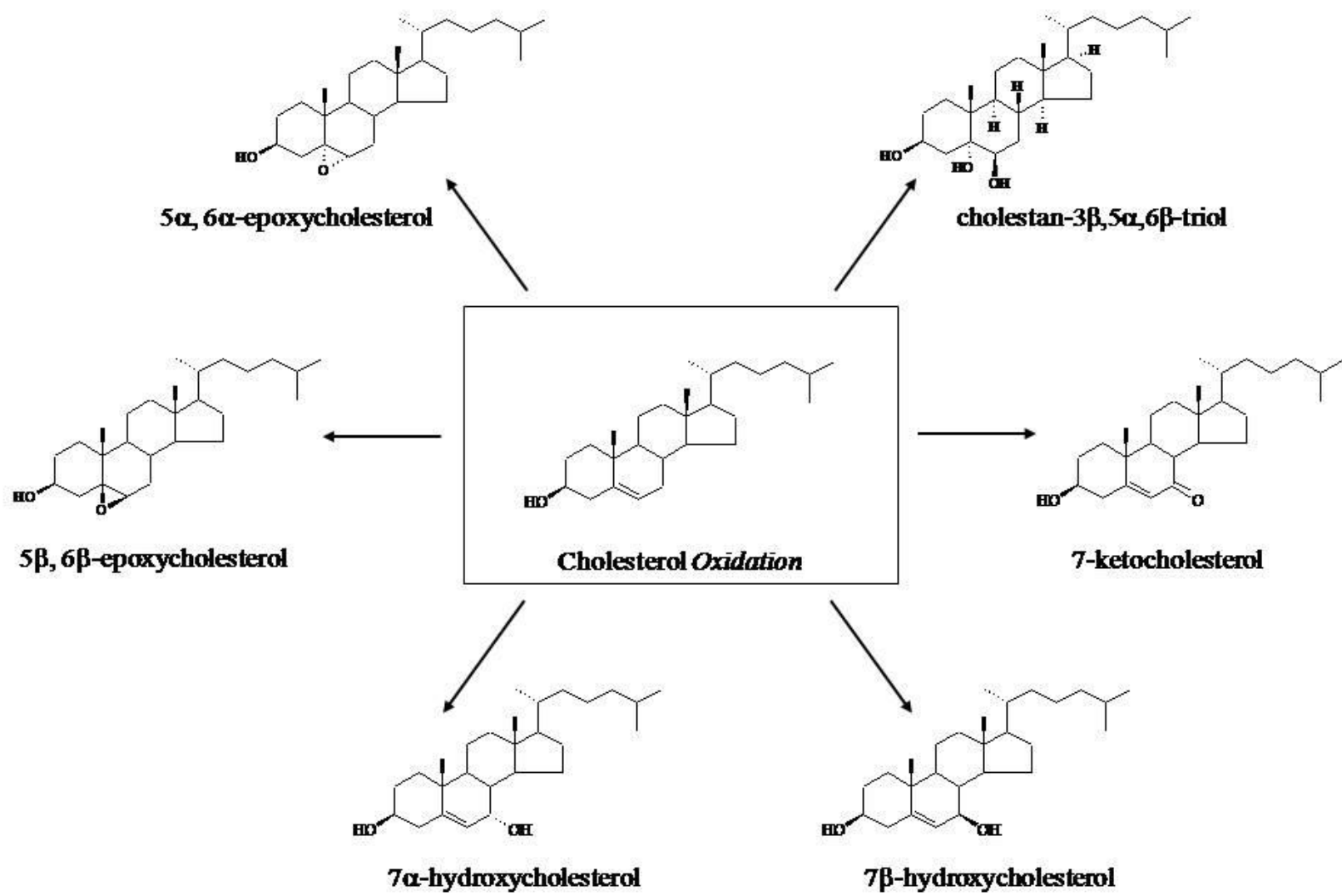

Figure 2. Structures of the major PUFA-derived oxidation products.

\subsection{Oxysterols' biological effects}

Oxysterols participate in many physiological processes, most of which are connected to cholesterol metabolism, including the biosynthesis of bile acids and the reverse cholesterol transport, but they also participate to steroidogenesis and vitamin D synthesis [68-70, 73-76].

Moreover, the addition of a carbonyl, hydroxyl, or epoxide moiety on the cholesterol structure alters its 3dimensional shape and lipid packing, and enhances its hydrophilicity. It follows that oxysterols perturb the fluidity and permeability of the biomembranes where they insert, and are able to affect the activity of membrane-bound enzymes [76]. They can also pass through lipophilic membranes more easily than can cholesterol, and are redistributed more efficiently into the cells $[77,78]$, where they act as potent molecular regulators $[69,79]$.

For all these reasons, oxysterols are now considered to be important mediators of cholesterol-induced effects exerting pro-oxidant, pro-inflammatory, and pro-apoptotic activities, which link them to the pathogenesis of major chronic diseases including gut diseases $[72,79,80]$. 
Like other lipid peroxidation products, it is now demonstrated that cholesterol oxidation products promote and sustain inflammatory events, by inducing both the expression and synthesis of several cytokines, interleukins, and adhesion molecules; this probably involves redox-sensitive signaling pathways and factors, e.g. NF- $\mathrm{BB}, \mathrm{AP}-1$ and MAPKs [80].

Of note, it has recently been shown that $7 \mathrm{~K}$ is able to influence the behavior of macrophages, specifically by enhancing the M1 macrophage pro-inflammatory phenotype, and switching M2 macrophages to an intermediate phenotype characterized by increased production of pro-inflammatory mediators [81]. This has been reported for differentiated human peripheral blood monocytes, but the finding also supports the role of oxysterols as possible modulators of innate immune cells.

Differential proteome changes have also been induced in intestinal CaCo-2 cells after $7 \mathrm{~K}$-incubation: such incubation significantly increased the expression of several proteins implicated in lipid homeostasis, vesicle trafficking, fatty acid metabolism, mitochondrial membrane composition, immunosurveillance and cell proliferation [82].

The evidence that an oxysterol mixture stemming from the heating of dietary cholesterol exerts pro-inflammatory effects on human CaCo-2 enterocytes is in accordance with the hypothesis of a possible key role of oxysterols even in bowel inflammation; among the oxysterols present in the mixture, $7 \beta-\mathrm{OH}$ was the most effective [83]. In these cells the oxysterol-induced inflammation was confirmed to be mediated by NF-кB-MAPK signaling pathways [84]. Conversely, a previous study showed that $25-\mathrm{OH}$ but not $7 \beta-\mathrm{OH}$ significantly enhanced IL- 8 mRNA expression and synthesis in CaCo-2 cells stimulated with IL-1 $\beta$ [85].

Conversely, oxysterols derived from oxidative modification on the cholesterol side-chain are natural ligands of liver X receptor (LXR), a nuclear factor that has been related to the regulation of inflammatory processes $[72,76,86]$.

The LXR agonist 22(R)-OH inhibited TNF $\alpha$ expression in LPS-stimulated human colonic epithelial cells [87]. This evidence is in agreement with the anti-inflammatory effects demonstrated in primary macrophages for $22(\mathrm{R})-\mathrm{OH}$ and for the other natural LXR ligands 24-OH and 24(S),25-epoxycholesterol [88]. Overall the findings appear to indicate that endogenous oxysterols, not present at significant levels in food, specifically act differently than do species arising from food cholesterol auto-oxidation; they could thus be employed as therapeutic strategies against bowel diseases.

Another way in which oxysterols may contribute to sustaining inflammation-related gut diseases is by altering the properties of the intestinal epithelium. It was recently observed that $7 \mathrm{~K}$ not only reversed IL-10-expression induced in CaCo-2 cells by dendritic cells in co-cultures, but also diminished the transepithelial electrical resistance, a parameter 
reflecting CaCo-2 cell monolayer integrity. This finding is consistent with a down-regulation of tight junction protein zonula occludens- 1 in CaCo-2 cells. In the same model, $7 \mathrm{~K}$ also decreased IL-10 induction in dendritic cells; thus the overall data suggest that $7 \mathrm{~K}$ may impair the epithelial barrier, enhance the availability of antigens to the mucosal immune system including lamina propria DCs, and thus alter the inflammatory response in the gut mucosa [89].

Of note, major dietary oxysterols have been shown to possess marked cytotoxicity and to exert pro-apoptotic activity towards different cell types and tissues, including intestinal epithelial cells [90]; they might thereby compromise epithelial barrier integrity and function. Pro-apoptotic activity, in terms of caspase-3 and caspase-7 activation, was elicited by $7 \alpha-\mathrm{OH}, 7 \beta-\mathrm{OH}$ and $\alpha-\mathrm{EPOX}$, but not by a mixture of the three, when administered to undifferentiated CaCo-2 cells, suggesting an antitumoral role of specific cytotoxic oxysterols [91]. Conversely, an oxysterol mixture triggered the mitochondrial apoptotic pathway in differentiated colonic cells, but not in undifferentiated ones [92].

Analysis of the mechanisms underlying oxysterol-induced damage in greater depth points to ROS overproduction and oxidative stress exacerbation as the main event leading to gut injury. For example, increased ROS levels leading to mitochondrial perturbation and apoptosis were reported for $\mathrm{CaCo}-2$ cells exposed to 7 $\beta-\mathrm{OH}$ [93]. In the same cells the observed interleukin over-expression and apoptotic response appeared to be triggered by oxysterols through NOX1 activation and consequent intracellular ROS steady-state increase [83, 84, 91, 92].

Oxysterols might indirectly contribute to inflammatory and cell death processes by favoring the synthesis of AA, which is the precursor of eicosanoids and of several lipoperoxidation products of pathological relevance (see above). Indeed, an increase in the activity of $\Delta 6$-desaturase, a key enzyme in the conversion of LA to AA, has been found in rats fed an oxysterol enriched diet [94-96].

Oxysterols may also display their pathological activity through inflammasome activation, as recently reported for different cell types. 7-Ketocholesterol appeared to favor microglia cell activation and polarization to a pro-inflammatory M1 state via NLRP3 activation [97]. Furthermore, the same oxysterol stimulated inflammasome formation in bone marrow-derived cells, leading to IL-1 $\beta$ production [98]. 7-Ketocholesterol also appeared to induce secretion of the processed form of caspase-1 by murine primary macrophages, in an NLRP3 inflammasome dependent manner [99].

Notably, 25-OH, which mainly derives from enzymatic reactions, appeared to repress IL-1 activating inflammasome in response to Interferon signaling, in activated mouse macrophages [100]. 
The above findings point to the interactions between oxysterols and inflammasome complexes as a possible cause of gut inflammation, even if data are still lacking. In the light of the pro-oxidant properties of oxysterols and of the inflammasome signaling dependence on ROS [101, 102], investigations into their interplay might provide new insights into the development of bowel diseases.

\subsection{Potential oxysterol and bile acid partnership in intestinal disease}

Lastly, an interesting new perspective concerning the possible role of cholesterol oxidation products in bowel disease etiopathology may arise from considering their connection with bile acids (BAs). Some of the main oxysterols are, indeed, formed as intermediates of classical or "alternative" BA biosynthetic pathways (i.e. 7 $\alpha-\mathrm{OH}, 27-\mathrm{OH}$ and 3 $\beta$-hydroxy-5-cholestenoic acid), while oxysterols of extra-hepatic origin can be transported to the liver, where they also are metabolized into BAs [72, 103, 104]. Some oxysterols, indeed, appear to be substrates for sterol 27hydroxylase, which is the first enzyme of the "alternative" pathway of BA synthesis, highly expressed in liver and macrophages $[69,70]$.

Because of these analogies it may be presumed that oxysterols share at least some of the chemical and biological properties that point to BAs as important players in promoting and sustaining bowel inflammation and dysfunction.

In this connection, BAs appear to enhance colonic fluid and electrolyte secretion, and to impair lipid digestion, thus leading to diarrhea and steatorrhea; BAs apparently increase intestinal mucosa permeability, likely as a consequence of direct epithelial toxicity or through impairment of the epithelial tight junctions [105, 106].

It has been observed that continuous exposure of intestinal cells to elevated level of certain hydrophobic BAs is correlated with greater susceptibility to colorectal carcinogenesis, mainly as a consequence of oxidative DNA damage $[107,108]$.

Conversely, beneficial effects have been ascribed to BAs, in particular as promoters of mucosal epithelial integrity and modulators of anti-inflammatory responses in immune cells [105, 108].

Athough the data are somewhat controversial, the oxysterol-dependent regulation of key enzymes of BA metabolism has been reported [104]. For example, hepatic microsomal $7 \alpha$-hydroxylase activity can be either inhibited or increased by different oxysterols [109].

As has already been said, side chain oxidized oxysterols are ligands of LXR, which regulates BA excretion and cholesterol transport by controlling the expression of members of the ATP-binding cassette membrane transporters in the intestine and in macrophages $[72,86]$.

Taking these findings together, it is reasonable to think that oxysterols, in their turn, may contribute to the regulation/impairment of the BA pool in the intestine, thus being indirect modulators of the effects ascribed to them. 
Lastly, gut microbiota is fundamental in BA metabolism, since it enzymatically converts primary BAs to secondary BAs in the colon [110]. In the case of gut dysbiosis, a feature typical of IBD patients, BA dysmetabolism occurs and potentially triggers pro-inflammatory responses in colonic epithelium [105].

Similarly, although the possibility of oxysterol modification by gut microbiota has not yet been explored, it certainly cannot be ruled out. Its consequence might be the formation of compounds having varying degrees of harmful effects which in turn could affect intestinal condition.

\section{Possible therapeutic approaches}

Conventional therapy on intestinal inflammatory diseases mainly entails long-term treatment with 5aminosalicylates (5-ASA) and corticosteroids as classical anti-inflammatory agents reducing the formation of eicosanoids via COX2. More recently, treatments with immunomodulators and biological agents have been accepted in order to reduce immune system hyper-responsiveness in IBD patients with inadequate response to the standard treatment with 5-ASA and steroids. The use of anti-TNF $\alpha$ antibody is now considered as the mainstream treatment for improving mucosal healing and these patients' quality of life $[111,112]$. However, duration or discontinuation of anti$\mathrm{TNF} \alpha$ therapy associated with important side effects with risk of relapse is still debated [113].

Interestingly, the potential mechanism of action attributed to 5-ASA as ROS/RNS scavenger [114, 115] supports the hypothesis of the important role of oxidative stress in intestinal inflammatory diseases.

Recent developments in molecular medicine point to design a proper supplementation with antioxidants that can target selective molecules involved in redox signaling, as well as with specific lipids able to increase cell antioxidant response, induce anti-inflammatory derivatives, and diminish the formation of lipid oxidation end products. Modulating NF- $\kappa \mathrm{B}$ signaling and targeting ROS overproduction sites, such as plasma-membrane NOX and mitochondria, may provide promising therapeutic options to decrease intestinal damage $[2,116]$.

The importance of the maintenance of high antioxidant intestinal levels comes from experimental animal models of colitis, in which the improvement of colonic mucosa damage was observed after administration of GSH or its precursor N-acetylcysteine (NAC) [117, 118]. GSH supplementation significantly prevented lipid peroxidation associated with improved tissue damage [117].

IL-1 $\beta$ release and caspase- 1 activity, which are closely related to NLRP3 activation in experimental DSS-induced colitis, were significantly decreased in murine peritoneal macrophages by MAPK kinase inhibitors, and NAC [119].

In this perspective, special nutritional regimens counteracting or preventing intestinal inflammation could be considered. For instance, a comprehensive mixture of aminoacids and vitamins A, C, and E are employed in parenteral 
nutrition, a commonly used procedure in patients with gastrointestinal disorders in order to maintain adequate nutritional status. Supplemental antioxidant vitamins added to enteral feeding solutions have been reported to ameliorate disease severity in critically ill patients associated with a resistance to oxidative stress measured in plasma in terms of TBARs and low density lipoprotein oxidation [120].

During disease remission the resolution of acute inflammation requires a temporal switch from pro- to antiinflammatory eicosanoids, and their fatty acid precursors. Lymphocytes and macrophages can contribute to resolve inflammation through endogenous generation of specific $\omega 3$ - and $\omega 6$-PUFA derivatives with anti-inflammatory and pro-resolving activity. Among these products, resolvins and protectins derive from the degradation of $\omega 3$-PUFAs, and are potent bioactive compounds that exert their anti-inflammatory function by blocking trans-endothelial leukocyte migration and infiltration [121]. The administration of exogenous resolvin E1 protects against colitis development in mice by reducing leukocyte peritoneal infiltration and increasing survival and histological scores. The reduction of NF$\kappa \mathrm{B}$ phosphorylation and expression, together with a decrease in TNF $\alpha$, IL-1 $\beta$, and IL-6 were also observed [122, 123]. Resolvins are also generated after 5-ASA treatment because they are formed by aspirin-dependent acetylated form of COX2. Systemic treatment with aspirin-triggered resolvins D1 and D2, or 17-hydroxy-DHA D1-precursor was demonstrated to improve disease activity index and reduce colonic cytokines and adhesion molecules levels, as well as $\mathrm{NF}-\kappa \mathrm{B}$ expression in mice models of colitis [124]. This evidence provides a basis for understanding a novel mechanism of action of both non-steroidal anti-inflammatory drugs and dietary $\omega 3$-PUFA supplementation counteracting intestinal inflammation. Therefore, dietary supplementation with $\omega 3$-PUFAs may be promising in minimizing or preventing inflammatory diseases because of their potential action as substrates for anti-inflammatory eicosanoids' production. However, there are not enough data proving their beneficial effects, and there is still no consensus on $\omega 3$-dietary recommendations for IBD patients [125].

Dietary supplementation with polyphenols has recently attracted much attention as an alternative natural approach to prevent or treat chronic inflammatory diseases because of their strong antioxidant and anti-inflammatory properties. Polyphenols are a heterogeneous group of plant secondary metabolites that can be introduced with the diet. Therefore, they reach their highest concentration in the gut, where they can exert their peak of activity. Solid experimental proofs in intestinal cells as well in animal models of colitis showed a marked ability of polyphenols in reducing intestinal injury by modulating inflammatory and immune responses [33, 112]. For instance, quercetin has been found to improve intestinal barrier function by enhancing the expression of claudin-4 tight junction protein in intestinal CaCo-2 cells [126]. Polyphenols present in wine, as well as in green tea, were able to modulate intestinal inflammation induced by dietary oxysterols in enterocyte-like cells by suppressing pro-inflammatory cytokine 
formation $[83,127]$. Numerous signals appear to be regulated by these compounds. NOX1 and p38 MAPK activities have been shown to be negatively regulated by specific polyphenols present in wine. The down-stream transcriptional factor mainly involved in the cellular regulation by polyphenols appears to be NF-kB [84]. Polyphenols also show prebiotic activity by inhibiting the growth of detrimental bacteria and stimulating beneficial bacteria such as Lactobacteria and Bifidobacteria in the gut [128, 129].

Despite several studies on experimental models, epidemiological trials suggesting a positive association between fruit/vegetable consumption and human intestinal inflammation are still limited [130].

\section{CONCLUSIONS}

This review has examined the current understanding on the emerging molecular role of lipid oxidation products in the pathogenesis of inflammatory intestinal diseases.

Special emphasis was given to the detrimental role played by IsoPs, acrolein, MDA and HNE produced during membranes lipid peroxidation, as well as oxysterols generated by cholesterol oxidation during inflammation-associated redox changes.

Most of these molecules have shown to be reliable biomarkers of oxidative stress because of their high levels in biological fluids and intestinal tissue. Therefore, they could represent an important prognostic value in the evaluation of the different stages of inflammatory diseases.

The clinical significance of oxidative stress in IBD is now becoming clear, and may soon lead to new therapeutic options to ameliorate intestinal damage in this disease.

As a consequence, nutritional regimens with specific antioxidants and anti-inflammatory compounds could counteract or at least prevent gut disease development or progression.

\section{LIST OF ABBREVIATIONS}

22-OH: 22-hydroxycholesterol;

24-OH: 24-hydroxycholesterol;

25-OH: 25-hydroxycholesterol;

27-OH: 27-hydroxycholesterol;

5-ASA: 5-aminosalicylates;

7-K: 7-ketocholesterol; 
7 $\alpha-\mathbf{O H}: 7 \alpha$-hydroxycholesterol;

7 $\beta$-OH: 7 $\beta$-hydroxycholesterol;

8-OHdG: 8-hydroxy-2'-deoxyguanosine;

AA: arachidonic acid;

Acr-dG: acrolein-deoxyguanosine;

Akt: protein kinase B;

AP-1: activator protein-1;

BA: bile acid;

CD: Crohn's disease;

COX: ciclooxygenase;

CRC: colorectal cancer;

DHA: docosahexaenoic acid;

DSS: dextran sulfate sodium;

ERK: extracellular signal-regulated kinase;

GC/MS: Gas Chromatography/Mass Spectrometry;

GSH: glutathione;

HNE: 4-hydroxynonenal;

HNE-dG: HNE-deoxyguanosine;

HO-1: heme oxygenase-1;

HPLC: High Performance Liquid Chromatography;

IBD: inflammatory bowel disease;

IL: interleukin;

IsoPs: isoprostanes;

JNK: c-Jun N-terminal kinase;

LA: linoleic acid;

LOX: lipooxygenase;

LT: leukotriene;

LXR: liver X receptor;

MAPK: mitogen activated protein kinase;

MDA: malondialdehyde;

NAC: N-acetylcysteine; 
NADPH: nicotinamide adenine dinucleotide phosphate;

$\mathbf{N F - \kappa B : ~ n u c l e a r ~ f a c t o r - \kappa B ; ~}$

NLRP1: NLR family pyrin domain containing 1;

NLRP3: NLR family pyrin domain containing 3;

NLRs: NOD-like receptors;

NOD: nucleotide-binding oligomerization domain;

NOX: NADPH oxidase;

NRF2: nuclear factor-erythroid 2-related facyor 2;

p38: protein 38;

PGs: prostaglandins;

PI3K: phosphoinositide 3-kinase;

PUFA: polyunsaturated fatty acid;

RNS: reactive nitrogen species;

ROS: reactive oxygen species;

TBA: thiobarbituric acid;

TBARS: TBA reactive substances;

TNBS: 2,4,6-trinitrobenzene sulfonic acid;

TNF: tumor necrosis factor;

TRIOL: cholestan-3 $\beta, 5 \alpha, 6 \beta$-triol;

TRL: toll like receptor;

UC: ulcerative colitis;

$\alpha$-EPOX: $5 \alpha, 6 \alpha$-epoxycholesterol;

$\beta$-EPOX: $5 \beta, 6 \beta$-epoxycholesterol.

\section{CONFLICT OF INTEREST}

The authors confirm that this article content has no conflict of interest.

\section{ACKNOWLEDGEMENTS}


The authors thank the University of Turin [POLG_RILO_16_01, 2016], Italy, for supporting this work.

\section{REFERENCES}

[1] Quigley, E. M. M. Overlapping irritable bowel syndrome and inflammatory bowel disease: less to this than meets the eye? Therap. Adv. Gastroenterol., 2015, 9(2), 199-212.

[2] Biasi, F.; Leonarduzzi, G.; Oteiza, P. I.; Poli, G. Inflammatory bowel disease: mechanisms, redox considerations, and therapeutic targets. Antioxid. Redox Signal., 2013, 19(14), 1711-1747.

[3] Zezos, P.; Saibil, F. Inflammatory Pouch Disease: The Spectrum of Pouchitis. World J. Gastroenterol., 2015, 21(29), 8739-8752.

[4] Kim, E. R.; Chang, D. K. Colorectal cancer in inflammatory bowel disease: the risk, pathogenesis, prevention and diagnosis. World J. Gastroenterol., 2014, 20 (29), 9872-9881.

[5] Karin, M. Nuclear Factor-kappaB in Cancer Development and Progression. Nature, 2006, 441 (7092), $431-436$.

[6] Jones, R., M.; Neish, A., S. Redox Signaling Mediated by the Gut Microbiota. Free Radic. Biol. Med., 2016, S08915849(16), 30977-30987.

[7] Bauer, C.; Duewell, P.; Mayer, C.; Lehr, H., A.; Fitzgerald, K., A.; Dauer, M.; Tschopp, J.; Endres, S.; Latz, E.;

Schnurr, M. Colitis induced in mice with dextran sulfate sodium (DSS) is mediated by the NLRP3 inflammasome. Gut, 2010, 59(9), 1192-1199.

[8] Sorbara, M., T.; Girardin, S., E. Mitochondrial ROS fuel the inflammasome. Cell Res., 2011, 21(4), 558-560.

[9] Dennis, E. A.; Norris, P. C. Eicosanoid Storm in Infection and Inflammation. Nat. Rev. Immunol., 2015, 15(8), 511523.

[10] Milne, G. L.; Dai, Q.; Roberts, L. J. The Isoprostanes-25 Years Later. Biochim.Biophys. Acta., 2015, 1851(4), 433445.

[11] Yin, H.; Xu, L.; Porter, N. A. Free Radical Lipid Peroxidation: Mechanisms and Analysis. Chem. Rev., 2011, $111(10), 5944-5972$.

[12] Jahn, U.; Galano, J. M.; Durand, T. Beyond Prostaglandins - Chemistry and Biology of Cyclic Oxygenated Metabolites Formed by Free-Radical Pathways from Polyunsaturated Fatty Acids. Angew. Chem. Int. Ed. Engl., 2008, 47(32), 5894-5955.

[13] Wang, D.; Dubois, R., N. The role of COX-2 in intestinal inflammation and colorectal cancer. Oncogene, 2010, 29(6), 781-788. 
[14] Czerska, M.; Zieliński, M.; Gromadzińska, J. Isoprostanes - A Novel Major Group of Oxidative Stress Markers. Int. J. Occup. Med. Environ. Health., 2016, 29(2), 179-190.

[15] Noschka, E.; Werre, S. R.; Crisman, M. V.; Thatcher, C. D.; Milne, G. L.; Dahlgren, L. A. Implications of urine F2-isoprostane metabolite concentration in horses with colic and its potential use as a predictor for surgical intervention. Equine Vet. J., 2011, 43(SUPPL.39), 34-41.

[16] Stucchi, A. F.; Shofer, S.; Leeman, S.; Materne, O.; Beer, E.; McClung, J.; Shebani, K.; Moore, F.; O’Brien, M.; Becker, J. M. NK-1 antagonist reduces colonic inflammation and oxidative stress in dextran sulfate-induced colitis in rats. Am. J. Physiol. Gastrointest. Liver Physiol. 2000, 279(6), G1298-306.

[17] Porres, J. M.; Stahl, C. H.; Cheng, W. H.; Fu, Y.; Roneker, K. R.; Pond, W. G.; Lei, X. G. Dietary intrinsic phytate protects colon from lipid peroxidation in pigs with a moderately high dietary iron intake. Proc. Soc. Exp. Biol. Med. 1999, 221(44387), 80-86.

[18] Shebani, K. O.; Stucchi, a F.; McClung, J. P.; Beer, E. R.; LaMorte, W. W.; Becker, J. M. role of stasis and oxidative stress in ileal pouch inflammation. J. Surg. Res., 2000, 90(1), 67-75.

[19] Hassan, A.; Ibrahim, A.; Mbodji, K.; Coëffier, M.; Ziegler, F.; Bounoure, F.; Chardigny, J.-M.; Skiba, M.; Savoye, G.; Déchelotte, P.; Marion-Letellier, R. An $\alpha$-linolenic acid-rich formula reduces oxidative stress and inflammation by

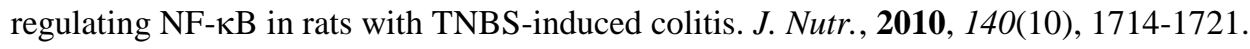

[20] Di Sabatino, A.; Santilli, F.; Guerci, M.; Simeone, P.; Ardizzone, S.; Massari, A.; Giuffrida, P.; Tripaldi, R.; Malara, A.; Liani, R.; Gurini, E.; Aronico, N.; Balduini, A.; Corazza, G. R.; Davì, G. Oxidative stress and thromboxanedependent platelet activation in inflammatory bowel disease: effects of anti-TNF- $\alpha$ Treatment. Thromb. Haemost., 2016, 116(3), 486-495.

[21] Huang, Y.; Lemberg, D. A.; Day, A. S.; Dixon, B.; Leach, S.; Bujanover, Y.; Jaffe, A.; Thomas, P. S. Markers of inflammation in the breath in paediatric inflammatory bowel disease. J. Pediatr. Gastroenterol. Nutr., 2014, 59(4), 505510.

[22] Aizenbud, D.; Aizenbud, I.; Reznick, A., Z.; Avezov, K. Acrolein-an $\alpha, \beta$-unsaturated aldehyde: a review of oral cavity exposure and oral pathology effects. Rambam Maimonides Med. J., 2016, 7(3).

[23] Moghe, A.; Ghare, S.; Lamoreau, B.; Mohammad, M.; Barve, S.; McClain, C.; Joshi-Barve, S. Molecular mechanisms of acrolein toxicity: relevance to human disease. Toxicol., 2015, 143(2), 242-255.

[24] Zarkovic, N.; Cipak, A.; Jaganjac, M.; Borovic, S.; Zarkovic, K. Pathophysiological relevance of aldehydic protein modifications. J. Proteomics, 2013, 92, 239-247.

[25] Zarkovic, K.; Uchida, K.; Kolenc, D.; Hlupic, L.; Zarkovic, N. Tissue distribution of lipid peroxidation product acrolein in human colon carcinogenesis. Free Radic. Res., 2006, 40(6), 543-552. 
[26] Zu, X.; Yan, R.; Pan, J.; Zhong, L.; Cao, Y.; Ma, J.; Cai, C.; Huang, D.; Liu, J.; Chung, F. L.; Liao, D. F.; Cao, D. Aldo-keto reductase 1B10 protects human colon cells from dna damage induced by electrophilic carbonyl compounds. Mol. Carcinog., 2017, 56(1), 118-129.

[27] Pan, J.; Keffer, J.; Emami, A.; Ma, X.; Lan, R.; Goldman, R.; Chung, F. L. Acrolein-derived dna adduct formation in human colon cancer cells: its role in apoptosis induction by docosahexaenoic acid. Chem. Res. Toxicol., 2009, 22(5), 798-806.

[28] Li, J.; Teng, Y.; Liu, S.; Wang, Z.; Chen, Y.; Zhang, Y.; Xi, S.; Xu, S.; Wang, R.; Zou, X. Cinnamaldehyde affects the biological behavior of human colorectal cancer cells and induces apoptosis via inhibition of the PI3K/Akt signaling pathway. Oncol. Rep. 2016, 35(3), 1501-1510.

[29] Long, M.; Tao, S.; De La Vega, M. R.; Jiang, T.; Wen, Q.; Park, S. L.; Zhang, D. D.; Wondrak, G. T. Nrf2dependent suppression of azoxymethane/dextran sulfate sodium-induced colon carcinogenesis by the cinnamon-derived dietary factor cinnamaldehyde. Cancer Prev. Res., 2015, 8(5), 444-454.

[30] Yan, H.; Wang, H.; Zhang, X.; Li, X.; Yu, J. Ascorbic acid ameliorates oxidative stress and inflammation in dextran sulfate sodium-induced ulcerative colitis in mice. Int. J. Clin. Exp. Med., 2015, 8(11), 20245-20253.

[31] Shi, L.; Lin, Q.; Yang, T.; Nie, Y.; Li, X.; Liu, B.; Shen, J.; Liang, Y.; Tang, Y.; Luo, F.; Oral administration of lentinus edodes $\beta$-glucans ameliorates DSS-induced ulcerative colitis in mice via MAPK-Elk-1 and MAPK-PPAR $\gamma$ pathways. Food Funct., 2016, 7(11), 4614-4627.

[32] Fei, L.; Xu, K. Zhikang Capsule ameliorates dextran sodium sulfate-induced colitis by inhibition of inflammation, Apoptosis, Oxidative Stress and MyD88-Dependent TLR4 Signaling Pathway. J. Ethnopharmacol., 2016, 192, 236247.

[33] Triantafillidis, J.; Vagianos, C.; Agrogiannis, G.; Gikas, A.; Douvi, G.; Syrmos, N.; Patsouris, E.; Papalois, A. Effect of infliximab and adalimumab on experimental colitis following orally supplemented iron. J. Invest. Surg., 2016, $18,1-7$

[34] Chassaing, B.; Aitken, J. D.; Malleshappa, M.; Vijay-Kumar, M. Dextran sulfate sodium (DSS)-induced colitis in mice. Curr. Protoc. Immunol., 2014, 104, Unit 15.25.

[35] Westbrook, A., M.; Szakmary, A.; Schiestl, R., H. Mouse models of intestinal inflammation and cancer. Arch Toxicol., 2016 90(9), 2109-2130.

[36] Tüzün, A.; Erdil, A.; Inal, V.; Aydin, A.; Bağci, S.; Yeşilova, Z.; Sayal, A.; Karaeren, N.; Dağalp, K. oxidative stress and antioxidant capacity in patients with inflammatory bowel disease. Clin. Biochem., 2002, 35 (7), $569-572$.

[37] Karp, S., M.; Koch, T., R. Oxidative stress and antioxidants in inflammatory bowel disease. Dis. Mon., 2006, 52(5), 199-207. 
[38] Boehm, D.; Krzystek-Korpacka, M.; Neubauer, K.; Matusiewicz, M.; Paradowski, L.; Gamian, A. lipid peroxidation markers in Crohn's disease: the associations and diagnostic value. Clin. Chem. Lab. Med., 2012, 50(8), 1359-1366.

[39] Mouzaoui, S.; Djerdjouri, B.; Makhezer, N.; Kroviarski, Y.; El-Benna, J.; Dang, P. M. C. Tumor necrosis factor- $\alpha-$ induced colitis increases NADPH oxidase 1 expression, oxidative stress, and neutrophil recruitment in the colon: preventive effect of apocynin. Mediators Inflamm. 2014, 2014, 312484.

[40] Beltŕan, B.; Nos, P.; Dasí, F.; Iborra, M.; Bastida, G.; Martínez, M.; O’Connor, J. E.; Sáez, G.; Moret, I.; Ponce, J. Mitochondrial dysfunction, persistent oxidative damage, and catalase inhibition in immune cells of naive and treated Crohn's disease. Inflamm. Bowel Dis., 2010, 16(1), 76-86.

[41] Novak, E. A.; Mollen, K. P. Mitochondrial dysfunction in inflammatory bowel disease. Front. cell Dev. Biol., 2015, 3, 62 .

[42] Meagher, E. A.; Fitzgerald, G. A. Indices of lipid peroxidation in vivo: strengths and limitations. Free Radic. Biol. Med., 2000, 28(12), 1745-1750.

[43] Poli, G.; Schaur, R. J.; Siems, W. G.; Leonarouzzi, G. 4-Hydroxynonenal: a membrane lipid pxidation product of medicinal interest. Med. Res. Rev., 2008, 28(4), 569-631.

[44] Weber, D.; Milkovic, L.; Bennett, S. J.; Griffiths, H. R.; Zarkovic, N.; Grune, T. Measurement of HNE-protein adducts in human plasma and serum by ELISA-comparison of two primary antibodies. Redox Biol., 2013, 1(1), 226233.

[45] Zelzer, S.; Mangge, H.; Oberreither, R.; Bernecker, C.; Gruber, H.-J.; Prüller, F.; Fauler, G. Oxidative Stress: Determination of 4-Hydroxy-2-Nonenal by Gas Chromatography/mass Spectrometry in Human and Rat Plasma. Free Radic. Res., 2015, 49(10), 1233-1238, 1-6.

[46] Surh, J.; Kwon, H. Estimation of daily exposure to 4-hydroxy-2-alkenals in Korean foods containing n-3 and n-6 polyunsaturated fatty acids. Food Addit. Contam., 2005, 22(8), 701-708.

[47] Guéraud, F.; Taché, S.; Steghens, J. P.; Milkovic, L.; Borovic-Sunjic, S.; Zarkovic, N.; Gaultier, E.; Naud, N.; Héliés-Toussaint, C.; Pierre, F.; Priymenko, N. Dietary polyunsaturated fatty acids and heme iron induce oxidative stress biomarkers and a cancer promoting environment in the colon of rats. Free Radic. Biol. Med., 2015, 83, 192-200. [48] Steppeler, C.; Haugen, J. E.; Rødbotten, R.; Kirkhus, B. Formation of Malondialdehyde, 4-Hydroxynonenal, and 4Hydroxyhexenal during in vitro digestion of cooked beef, pork, chicken, and salmon. J. Agric. Food Chem., 2016, 64(2), 487-496.

[49] Larsson, K.; Tullberg, C.; Alminger, M.; Havenaar, R.; Undeland, I. Malondialdehyde and 4-hydroxy-2-hexenal are formed during dynamic gastrointestinal in vitro digestion of cod liver oils. Food Funct., 2016, 7(8), 3458-3467. 
[50] Borovic, S.; Rabuzin, F.; Waeg, G.; Zarkovic, N. Enzyme-linked immunosorbent assay for 4-hydroxynonenalhistidine conjugates. Free Radic. Res., 2006, 40(8), 809-820.

[51] Castro, J. P.; Grune, T.; Siems, W. 4-Hydroxynonenal (HNE) modified proteins in metabolic diseases. Free Radic. Biol. Med., 2016, S0891-5849(16), 30986-30988.

[52] Milkovic, L.; Cipak Gasparovic, a.; Zarkovic, N. Overview on major lipid peroxidation bioactive factor 4 hydroxynonenal as pluripotent growth-regulating factor. Free Radic. Res., 2015, 49(7), 850-860.

[53] Csala, M.; Kardon, T.; Legeza, B.; Lizák, B.; Mandl, J.; Margittai, Éva; Puskés, F.; Száraz, P.; Szelényi, P.; Bánhegyi, G. On the role of 4-hydroxynonenal in health and disease. Biochim. Biophys. Acta, 2015, 18525), 826-838. [54] Biasi, F.; Tessitore, L.; Zanetti, D.; Cutrin, J. C.; Zingaro, B.; Chiarpotto, E.; Zarkovic, N.; Serviddio, G.; Poli, G. Associated changes of lipid peroxidation and transforming growth factor beta1 levels in human colon cancer during tumour progression. Gut, 2002, 50(3), 361-367.

[55] Lee, I. A.; Bae, E. A.; Hyun, Y. J.; Kim, D. H. Dextran sulfate sodium and 2,4,6-trinitrobenzene sulfonic acid induce lipid peroxidation by the proliferation of intestinal gram-negative bacteria in mice. J Inflamm (Lond)., $2010,7,7$. [56] Shaker, M. E.; Ashamallah, S. A.; Houssen, M. E. Celastrol ameliorates murine colitis via modulating oxidative stress, inflammatory cytokines and intestinal homeostasis. Chem. Biol. Interact., 2014, 210(1), 26-33.

[57] Scharlau, D.; Borowicki, A.; Habermann, N.; Hofmann, T.; Klenow, S.; Miene, C.; Munjal, U.; Stein, K.; Glei, M. Mechanisms of primary cancer prevention by butyrate and other products formed during gut flora-mediated fermentation of dietary fibre. Mutat. Res., 2009, 682(1), 39-53.

[58] Nair, J.; Gansauge, F.; Beger, H.; Dolara, P.; Winde, G.; Bartsch, H. Increased Etheno-DNA adducts in affected tissues of patients suffering from crohn's disease, ulcerative colitis, and chronic pancreatitis. Antioxid. Redox Signal., 2006, $8(5), 1003-1010$

[59] Skrzydlewska, E.; Sulkowski, S.; Koda, M.; Zalewski, B.; Kanczuga-Koda, L.; Sulkowska, M. Lipid peroxidation and antioxidant status in colorectal cancer. World J. Gastroenterol., 2005, 11 (3), 403-406.

[60] Cerbone, A.; Toaldo, C.; Laurora, S.; Briatore, F.; Pizzimenti, S.; Dianzani, M. U.; Ferretti, C.; Barrera, G. 4Hydroxynonenal and PPARgamma ligands affect proliferation, differentiation, and apoptosis in colon cancer cells. Free Radic. Biol. Med., 2007, 42 (11), 1661-1670.

[61] Pizzimenti, S.; Menegatti, E.; Berardi, D.; Toaldo, C.; Pettazzoni, P.; Minelli, R.; Giglioni, B.; Cerbone, A.; Dianzani, M. U.; Ferretti, C.; Barrera, G. 4-hydroxynonenal, a lipid peroxidation product of dietary polyunsaturated fatty acids, has anticarcinogenic properties in colon carcinoma cell lines through the inhibition of telomerase activity. $J$. Nutr. Biochem., 2010, 21 (9), 818-826. 
[62] Furfaro, A. L.; Traverso, N.; Domenicotti, C.; Piras, S.; Moretta, L.; Marinari, U. M.; Pronzato, M. A.; Nitti, M. The Nrf2/HO-1 axis in cancer cell growth and chemoresistance. Oxid. Med. Cell. Longev., 2016, 2016, 1958174. [63] Biasi, F.; Vizio, B.; Mascia, C.; Gaia, E.; Zarkovic, N.; Chiarpotto, E.; Leonarduzzi, G.; Poli, G. C-Jun N-terminal kinase upregulation as a key event in the proapoptotic interaction between transforming growth factor-beta1 and 4hydroxynonenal in colon mucosa. Free Radic. Biol. Med., 2006, 41 (3), 443-454

[64] Biasi, F.; Mascia, C.; Poli, G. The Contribution of Animal Fat Oxidation Products to Colon Carcinogenesis, through Modulation of TGF- $\beta 1$ Signaling. Carcinogenesis., 2008, 29(5), 890-894.

[65] Cindric, M.; Cipak, A.; Zapletal, E.; Jaganjac, M.; Milkovic, L.; Waeg, G.; Stolc, S.; Zarkovic, N.; Suzana Borovic, S. Stobadine Attenuates Impairment of an Intestinal Barrier Model Caused by 4-Hydroxynonenal. Toxicol In Vitro, 2013, 27(1), 426-432.

[66] Kimura, H.; Mukaida, M.; Kuwabara, K.; Ito, T.; Hashino, K.; Uchida, K.; Matsumoto, K.; Yoshida, K. 4 Hydroxynonenal modifies IgA in rat intestine after lipopolysaccharide injection. Free Radic. Biol. Med., 2006, 41(6), 973-978.

[67] Smith, L., L.; Johnson, B., H. Biological activities of oxysterols. Free Radic. Biol. Med., 1989, 7(3), $285-332$.

[68] Schroepfer, G. J. Oxysterols: Modulators of Cholesterol Metabolism and Other Processes. Physiol. Rev., 2000, $80(1), 361-554$

[69] Mutemberezi, V.; Guillemot-Legris, O.; Muccioli, G. G. Oxysterols: From Cholesterol Metabolites to Key Mediators. Prog Lipid Res., 2016, 64, 152-169.

[70] Brown, A., J.; Jessup, W.; Oxysterols: Sources, cellular storage and metabolism, and new insights into their roles in cholesterol homeostasis. Mol. Aspects Med., 2009, 30(3), 111-122.

[71] Lordan, S.; Mackrill, J., J.; O’Brien, N. M. Oxysterols and Mechanisms of Apoptotic Signaling: Implications in the Pathology of Degenerative Diseases. J. Nutr. Biochem., 2009, 20, 321-336.

[72] Garenc, C.; Julien, P.; Levy, E. Oxysterols in biological systems: the gastrointestinal tract, liver, vascular wall and central nervous system. Free Radic. Res., 2010, 44(1), 47-73.

[73] Midzak, A.; Papadopoulos, V. Binding domain-driven intracellular trafficking of sterols for synthesis of steroid hormones, bile acids and oxysterols. Traffic, 2014, 15(9), 895-914.

[74] Nelson, E., R.; Wardell., S., E.; McDonnell., D., P. The molecular mechanisms underlying the pharmacological actions of estrogens, SERMs and oxysterols: implications for the treatment and prevention of osteoporosis. Bone, 2013, $53(1), 42-50$.

[75] Bah, S., Y.; Dickinson, P.; Forster, T.; Kampmann, B.; Ghazal, P. Immune oxysterols: Role in mycobacterial infection and inflammation. J. Steroid Biochem. Mol. Biol., 2016, S0960-0760(16), 30111. 
[76] Olkkonen, V., M.; Hynynen, R. Interactions of oxysterols with membranes and proteins. Mol. Aspects Med., 2009, $30(3), 123-133$

[77] Van Amerongen, A.; Demel, R. A.; Westerman, J.; Wirtz, K. W. A. Transfer of cholesterol and oxysterol derivatives by the nonspecific lipid transfer protein (sterol carrier protein 2): A study on its mode of action. Biochim. Biophys. Acta (BBA)/Lipids Lipid Metab., 1989, 1004(1), 36-43.

[78] Kan, C. C.; Yan, J.; Bittman, R. Rates of spontaneous exchange of synthetic radiolabeled sterols between lipid vesicles. Biochemistry, 1992, 31(1987), 1866-1874.

[79] Sottero, B.; Gamba, P.; Gargiulo, S.; Leonarduzzi, G.; Poli, G. Cholesterol oxidation products and disease: an emerging topic of interest in medicinal chemistry. Curr. Med. Chem., 2009, 16(6), 685-705.

[80] Poli, G.; Biasi, F.; Leonarduzzi, G. Oxysterols in the pathogenesis of major chronic diseases. Redox Biol., 2013, l(1), 125-130.

[81] Buttari, B.; Segoni, L.; Profumo, E.; D’Arcangelo, D.; Rossi, S.; Facchiano, F.; Businaro, R.; Iuliano, L.; Rigano,

R. 7-Oxo-cholesterol potentiates pro-inflammatory signaling in human M1 and M2 macrophages. Biochem.

Pharmacol., 2013, 86(1), 130-137.

[82] Laparra, J. M.; Alfonso-García, A.; Alegría, A.; Barberá, R.; Cilla, A. 7keto-stigmasterol and 7keto-cholesterol induce differential proteome changes to intestinal epitelial (CaCo-2) cells. Food Chem. Toxicol., 2015, 84, 29-36.

[83] Mascia, C.; Maina, M.; Chiarpotto, E.; Leonarduzzi, G.; Poli, G.; Biasi, F. Proinflammatory effect of cholesterol and its oxidation products on CaCo-2 human enterocyte-like cells: Effective protection by epigallocatechin-3-gallate. Free Radic. Biol. Med., 2010, 49(12), 2049-2057.

[84] Guina, T.; Deiana, M.; Calfapietra, S.; Cabboi, B.; Maina, M.; Tuberoso, C., I.; Leonarduzzi, G.; Gamba, P.; Gargiulo, S.; Testa, G.; Poli, G.; Biasi, F. The role of p38 MAPK in the induction of intestinal inflammation by dietary oxysterols: modulation by wine phenolics. Food Funct., 2015, 6(4), 1218-1228.

[85] Bai, B.; Yamamoto, K.; Sato, H.; Sugiura, H.; Tanaka, T. Combined effect of 25-hydroxycholesterol and IL-1beta on IL-8 production in human colon carcinoma cell line (CaCo-2). Inflammation, 2005, 29(4-6), 141-146.

[86] Töröcsik, D.; Szanto, A.; Nagy, L. Oxysterol signaling links cholesterol metabolism and inflammation via the liver X receptor in macrophages. Mol Aspects Med., 2009, 30(3), 134-152.

[87] Jakobsson, T.; Vedin, L.; Hassan, T.; Venteclef, N.; Greco, D.; D’Amato, M.; Treuter, E.; Gustafsson, J.-Å.; Steffensen, K. R.; Amato, M. D.; et al. The oxysterol receptor LXR $\beta$ protects against DSS- and TNBS-induced colitis in mice. Mucosal Immunol., 2014, 7(6), 1416-1428. 
[88] Ghisletti, S.; Huang, W.; Ogawa, S.; Pascual, G.; Lin, M. E.; Willson, T. M.; Rosenfeld, M. G.; Glass, C. K. Parallel SUMOylation-dependent pathways mediate gene- and signal-specific transrepression by LXRs and PPAR $\gamma$. Mol. Cell., 2007, 25(1), 57-70.

[89] Chalubinski, M.; Wojdan, K.; Gorzelak, P.; Borowiec, M.; Broncel, M. The effect of oxidized cholesterol on barrier functions and IL-10 mRNA expression in human intestinal epithelium co-cultured with dendritic cells in the transwell system. Food Chem. Toxicol., 2014, 69, 289-293.

[90] De Weille, J.; Fabre, C.; Bakalara, N. Oxysterols in cancer cell proliferation and death. Biochem. Pharmacol., 2013, $86(1), 154-160$

[91] Biasi, F.; Chiarpotto, E.; Sottero, B.; Maina, M.; Mascia, C.; Guina, T.; Gamba, P.; Gargiulo, S.; Testa, G.; Leonarduzzi, G.; et al. Evidence of cell damage induced by major components of a diet-compatible mixture of oxysterols in human colon cancer CaCo-2 cell line. Biochimie, 2013, 95(3), 632-640.

[92] Biasi, F.; Mascia, C.; Astegiano, M.; Chiarpotto, E.; Nano, M.; Vizio, B.; Leonarduzzi, G.; Poli, G. Pro-oxidant and proapoptotic effects of cholesterol oxidation products on human colonic epithelial cells: a potential mechanism of inflammatory bowel disease progression. Free Radic. Biol. Med., 2009, 47(12), 1731-1741.

[93] Roussi, S.; Gossé, F.; Aoudé-Werner, D.; Zhang, X.; Marchioni, E.; Geoffroy, P.; Miesch, M.; Raul, F. Mitochondrial perturbation, oxidative stress and lysosomal destabilization are involved in $7 \beta$-hydroxysitosterol and $7 \beta$ hydroxycholesterol triggered apoptosis in human colon cancer cells. Apoptosis, 2007, 12(1), 87-96

[94] Osada, K.; Kodama, T.; Noda, S.; Yamada, K.; Sugano, M. Oxidized cholesterol modulates age-related change in lipid metabolism in rats. Lipids, 1995, 30(5), 405-413.

[95] Osada, K.; Kodama, T.; Yamada, K.; Nakamura, S.; Sugano, M. Dietary oxidized cholesterol modulates cholesterol metabolism and linoleic acid desaturation in rats fed high-cholesterol diets. Lipids, 1998, 33(8), 757-764. [96] Minehira, K.; Inoue, S.; Nonaka, M.; Osada, K.; Yamada, K.; Sugano, M. Effects of dietary protein type on oxidized cholesterol-induced alteration in age-related modulation of lipid metabolism and indices of immune function in rats. Biochim. Biophys. Acta - Mol. Cell Biol. Lipids, 2000, 1483(1), 141-153.

[97] Indaram, M.; Ma, W.; Zhao, L.; Fariss, R. N.; Rodriguez, I. R.; Wong, W. T. 7-Ketocholesterol increases retinal microglial migration, activation, and angiogenicity: a potential pathogenic mechanism underlying age-related macular degeneration. Sci. Rep., 2015, 5, 9144.

[98] Shi, G.; Chen, S.; Wandu, W. S.; Ogbeifun, O.; Nugent, L. F.; Maminishkis, A.; Hinshaw, S. J. H.; Rodriguez, I. R.; Gery, I. Inflammasomes induced by 7-ketocholesterol and other stimuli in RPE and in bone marrow-derived cells differ markedly in their production of IL-1 $\beta$ and IL-18. Investig. Ophthalmol. Vis. Sci., 2015, 56(3), 1658-1664. 
[99] Menu, P.; Pellegrin, M.; Aubert, J. F.; Bouzourene, K.; Tardivel, A.; Mazzolai, L.; Tschopp, J. Atherosclerosis in ApoE-deficient mice progresses independently of the NLRP3 inflammasome. Cell Death Dis., 2011, $2(3)$, e137. [100] Reboldi, A.; Dang, E. V; McDonald, J. G.; Liang, G.; Russell, D. W.; Cyster, J. G. Inflammation. 25Hydroxycholesterol suppresses interleukin-1-driven inflammation downstream of type I interferon. Science, 2014, 345(6197), 679-684.

[101] Martinon, F. Signaling by ROS drives inflammasome activation. Eur. J. Immunol., 2010, 40(3), 616-619.

[102] Haneklaus, M.; O’Neill, L. A. J.; Coll, R. C. Modulatory mechanisms controlling the NLRP3 inflammasome in inflammation: recent developments. Curr. Opin. Immunol., 2013, 25(1), 40-45.

[103] Zhou, H.; Hylemon, P. B. Bile acids are nutrient signaling hormones. Steroids, 2014, 86, $62-68$.

[104] Crosignani, A.; Zuin, M.; Allocca, M.; Del Puppo, M. Oxysterols in bile acid metabolism. Clin. Chim. Acta., 2011, 412(23-24), 2037-2045.

[105] Pavlidis, P.; Powell, N.; Vincent, R. P.; Ehrlich, D.; Bjarnason, I.; Hayee, B. Systematic review: Bile acids and intestinal inflammation-luminal aggressors or regulators of mucosal defence? Aliment. Pharmacol. Ther., 2015, 42(7), $802-817$

[106] Vítek, L. Bile acid malabsorption in inflammatory bowel disease. Inflamm. Bowel Dis., 2015, $21(2), 476-483$. [107] Mosele, J. I.; Macià, A.; Motilva, M. J. Metabolic and microbial modulation of the large intestine ecosystem by non-absorbed diet phenolic compounds: A review. Molecules, 2015, 20(9), 17429-17468.

[108] Sipka, S.; Bruckner, G. The immunomodulatory role of bile acids. Int. Arch. Allergy Immunol., 2014, 165(1), 1-8.

[109] Osada, K. Cholesterol Oxidation Product: Other Biological Effects In: Cholesterol and Phytosterol oxidation products: analysis, occurrence, and biological effects; Guardiola, F.; Dutta, P., C.; Codony, R.; Savage, P., G., Eds.; AOCS Press: Illinois, 2002, pp. 285-286.

[110] Ridlon, J. M.; Bajaj, J. S. The human gut sterolbiome: bile acid-microbiome endocrine aspects and therapeutics. Acta Pharm. Sin. B, 2015, 5(2), 99-105.

[111] Bernstein, C. N.; Fried, M.; Krabshuis, J. H.; Cohen, H.; Eliakim, R.; Fedail, S.; Gearry, R.; Goh, K. L.; Hamid, S.; Khan, A. G.; LeMair, A. W.; Malfertheiner; Ouyang, Q.; Rey, J. F.; Sood, A.; Steinwurz, F.; Thomsen, O. O.; Thomson, A.; Watermeyer, G. World Gastroenterology Organization Practice Guidelines for the Diagnosis and Management of IBD in 2010. Inflamm. Bowel Dis., 2010, 16(1), 112-124.

[112] Biasi, F.; Astegiano, M.; Maina, M.; Leonarduzzi, G.; Poli, G. Polyphenol Supplementation as a Complementary Medicinal Approach to Treating Inflammatory Bowel Disease. Curr. Med. Chem., 2011, 18(31), 4851-4865.

[113] Gisbert, J. P.; Marín, A. C.; Chaparro, M. The Risk of Relapse after Anti-TNF Discontinuation in Inflammatory Bowel Disease: Systematic Review and Meta-Analysis. Am. J. Gastroenterol., 2016, 111(5), 632-647. 
[114] Couto, D.; Ribeiro, D.; Freitas, M.; Gomes, A.; Lima, J. L. F. C.; Fernandes, E. Scavenging of Reactive Oxygen and Nitrogen Species by the Prodrug Sulfasalazine and Its Metabolites 5-Aminosalicylic Acid and Sulfapyridine. Redox Rep., 2010, 15(6), 259-267.

[115] Managlia, E.; Katzman, R. B.; Brown, J. B.; Barrett, T. a. Antioxidant properties of mesalamine in colitis inhibit phosphoinositide 3-kinase signaling in progenitor cells. Inflamm. Bowel Dis., 2013, 19(10), 2051-2060.

[116] Piechota-Polanczyk, A.; Fichna, J. Review Article: The Role of Oxidative Stress in Pathogenesis and Treatment of Inflammatory Bowel Diseases. Naunyn Schmiedebergs Arch. Pharmacol., 2014, 387(7), 605-620.

[117] Loguercio, C.; D’Argenio, G.; Delle Cave, M.; Cosenza, V.; Della Valle, N.; Mazzacca, G.; Del Vecchio Blanco, C. Glutathione supplementation improves oxidative damage in experimental colitis. Dig. Liver Dis., 2003, 35(9), 635641.

[118] You, Y.; Fu, J. J.; Meng, J.; Huang, G. D.; Liu, Y. H. Effect of N-acetylcysteine on the murine model of colitis induced by dextran sodium sulfate through up-regulating PON1 activity. Dig. Dis. Sci., 2009, 54(8), 1643-1650. [119] Kwon, K. H.; Ohigashi, H.; Murakami, A. Dextran Sulfate sodium enhances interleukin-1 beta release via activation of p38 MAPK and ERK1/2 pathways in murine peritoneal macrophages. Life Sci., 2007, 81(5), 362-371. [120] Preiser, J. C.; Van Gossum, a; Berré, J.; Vincent, J. L.; Carpentier, Y. Enteral feeding with a solution enriched with antioxidant vitamins A, C, and E enhances the resistance to oxidative stress. Crit. Care Med., 2000, 28(12), 38283832.

[121] Spite, M.; Clària, J.; Serhan, C. N. Resolvins, Specialized Proresolving Lipid Mediators, and Their Potential Roles in Metabolic Diseases. Cell Metab., 2014, 19(1), 21-36.

[122] Arita, M.; Yoshida, M.; Hong, S.; Tjonahen, E.; Glickman, J. N.; Petasis, N. A.; Blumberg, R. S.; Serhan, C. N. Resolvin E1, an endogenous lipid mediator derived from omega-3 eicosapentaenoic acid, protects against 2,4,6trinitrobenzene sulfonic acid-induced colitis., Proc. Natl. Acad. Sci. U. S. A., 2005, 102(21), 7671-7676.

[123] Ishida, T.; Yoshida, M.; Arita, M.; Nishitani, Y.; Nishiumi, S.; Masuda, A.; Mizuno, S.; Takagawa, T.; Morita, Y.; Kutsumi, H.; Inokuchi, H.; Serhan, C. N.; Blumberg, R. S.; Azuma, T. Resolvin E1, an endogenous lipid mediator derived from eicosapentaenoic acid, prevents dextran sulfate sodium-induced colitis. Inflamm. Bowel Dis., 2010, 16(1), $87-95$.

[124] Bento, A. F.; Claudino, R. F.; Dutra, R. C.; Marcon, R.; Calixto, J. B. Omega-3 fatty acid-derived mediators 17(R)-hydroxy docosahexaenoic acid, aspirin-triggered resolvin D1 and resolvin D2 prevent experimental colitis in mice. J. Immunol., 2011, 187(4), 1957-1969.

[125] Barbalho, S., M.; Goulart, R.de, A.; Quesada, K.; Bechara, M., D.; Carvalho, A.de, C. Inflammatory bowel disease: can omega-3 fatty acids really help? Ann. Gastroenterol., 2016, 29(1), 37-43. 
[126] Amasheh, M.; Schlichter, S.; Amasheh, S.; Mankertz, J.; Zeitz, M.; Fromm, M.; Schulzke, J., D. Quercetin enhances epithelial barrier function and increases claudin-4 expression in CaCo-2 cells. J. Nutr., 2008, 138(6), 10671073.

[127] Biasi, F.; Guina, T.; Maina, M.; Cabboi, B.; Deiana, M.; Tuberoso, C., I.; Calfapietra, S.; Chiarpotto, E.; Sottero, B.; Gamba, P.; Gargiulo, S.; Brunetto, V.; Testa, G.; Dessì, M., A.; Poli, G.; Leonarduzzi, G. Phenolic compounds present in Sardinian wine extracts protect against the production of inflammatory cytokines induced by oxysterols in CaCo-2 human enterocyte-like cells. Biochem. Pharmacol., 2013, 86(1), 138-145.

[128] Tabasco, R.; Sánchez-Patán, F.; Monagas, M.; Bartolomé, B.; Victoria Moreno-Arribas, M.; Peláez, C.; Requena, T. Effect of grape polyphenols on lactic acid bacteria and bifidobacteria growth: resistance and metabolism. Food Microbiol., 2011, 28(7), 1345-1352.

[129] Duda-Chodak, A.; Tarko, T.; Satora, P.; Sroka, P. Interaction of Dietary Compounds, Especially Polyphenols, with the Intestinal Microbiota: A Review. Eur. J. Nutr., 2015, 54(3), 325-341.

[130] Kaulmann, A.; Bohn, T. Bioactivity of Polyphenols: Preventive and Adjuvant Strategies toward Reducing Inflammatory Bowel Diseases - Promises, Perspectives, and Pitfalls. Oxid. Med. Cell. Longev., 2016, $2016,9346470$.

\section{Figure Legends}

Figure 1. Structures of the main oxysterols derived from cholesterol oxidation.

Figure 2. Structures of the major PUFA-derived oxidation products.

Graphical abstract. Oxidative stress-derived lipid oxidation products, LPOs and COPs, are involved in the induction and maintenance of an inflammatory microenvironment leading to intestinal damage. 